\title{
EL DIARIO COMO CUADERNO DE SILENCIOS
}

José Manuel TRABADO CABADO

Universidad de León

jose-manuel.trabado@unileon.es

Toda soledad al escribir es poca, todo silencio al escribir es poco, incluso la noche es demasiado poca noche.

Kafka en una carta a Felice, 14 de enero de 1913

El ser humano no solamente actúa, habla, piensa y sueña a lo largo de su vida, sino que también calla: durante toda nuestra vida callamos sobre quiénes somos, sobre ese ser que sólo nosotros conocemos y que no podemos revelar a nadie. Sin embargo, sabemos que el ser sobre quien callamos representa la verdad: ese ser somos nosotros mismos, y callamos sobre nosotros mismos.

Sandor Marai, ;Tierra, tierra!

Él va eligiendo nuevas lenguas para callar.

Elias Canetti, Apuntes

Me resulta difícil permanecer solitario, reflexionar, en consecuencia mantener con regularidad este diario.

Julio Ramón Ribeyro, La tentación del fracaso

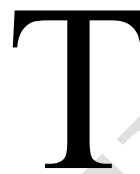

oda escritura parece haber definido su territorio como el de la soledad: «Toda soledad al escribir es poca» confesaba Kafka; Sandor Marai, por su parte, escribía en sus Confesiones de un burgués: «Tiene el alma un último refugio donde el escritor encuentra cobijo: buscamos la verdad, pero guardamos algo de libertad para nosotros mismos, algo que no compartimos con nadie». Si pensamos en la figura del alquimista del poema de Hopkins cuando afirmaba «The whole world passes; I stand by» parece abrirse ante nuestros ojos la idea de que escribir es una forma de estar en el mundo con el pie cambiado, de iniciarse en una paradójica forma de usar las palabras: la de convertirlas en un habla secreta que renuncia a ser oída de forma inmediata, que busca en lo diferido su naturaleza. Ese carácter de ocultación y exhibición cobra si cabe un mayor énfasis en una forma como el diario que nace, como toda escritura pero aquí de forma manifiesta y particularmente intensa, como algo soterrado y oculto, que se desarrolla posteriormente articulando silencios y que, finalmente y tras luchar con la idea del abandono, puede agotarse y desvanecer su voz en la nada. La constatación de 
esos silencios que orlan su escritura y la enmarcan junto con el examen somero de alguno de esos alcances es el propósito de estas líneas.

De varias formas puede hacer efectiva su actuación el silencio dentro del diario. Una, obvia como no podía ser de otra manera, está relacionada con la naturaleza estructural del diario. Se trata de una escritura en la que no existe ni puede haber plan alguno premeditado; su fluir lleva inscrito en su misma esencia una serie de brechas en las cuales se instalan momentos de silencio. No todos los días poseen una entrada en el diario; algunos periodos, que pueden ser incluso cruciales dentro de la vida de quien escribe el diario, no tienen correlato alguno en la escritura. El carácter fragmentario acentúa, por un lado, todo aquello que se consigna por escrito pero también, y de forma paradójica, aquellos lapsos de tiempo en los que el diario parece haber enmudecido. Los huecos que toda escritura encierra se hacen ahora visibles y hasta imprescindibles. Este hecho, que parece derivado de la propia naturaleza del diario, no deja de ser una consecuencia de la actuación de los mecanismos de la memoria y de cómo ésta elige ciertos hechos de la vida para magnificarlos. Sin embargo, el diario lucha contra la monotonía de un sin fin de días iguales que pueden anular la capacidad escritora. A este respecto me resulta sugerente la frase de la periodista Florence Aubenas del diario francés Libération, que declaró lo siguiente tras haber sufrido un secuestro de 175 días en Irak: «Un secuestro es muy largo de vivir y muy corto de contar» (País, 15 de junio de 2005) ${ }^{1}$. Parece evidente el desfase entre la experiencia vital y la capacidad narrativa. La narración no puede dar cuenta de lo vivido; posee su propia retórica que le exige momentos determinados de tensión y una lógica subyacente que ligue los hechos. No se amolda a estos resortes la experiencia vivida aun con ser dolorosa. La monotonía del dolor y el sufrimiento es escasamente narrable ya que no permite insertar esos puntos de inflexión que capten el interés lector. Parece, pues, que ciertas vivencias pueden llegar a instalar una percepción plana del tiempo que es imposible referir mediante una narración. Ése puede ser uno de los peligros con los que el silencio amenace la escritura del diario encaminada a formalizar la experiencia vital. De alguna manera esta escritura lucha contra ese tiempo plano para otorgar un cierto relieve al fluir temporal: convertir el continuum vital en algo discernible al que se le puede otorgar sentido ${ }^{2}$. La escritura del diario puede ser en ocasiones una cartografía de lo nimio e insignificante que ahora queda perfectamente señalado. De manera muy sutil se puede encontrar esa percepción en una de las Prosas apátridas de Julio Ramón Ribeyro:

Mi gato negro y yo, en esta noche lluviosa de verano. La pieza silenciosa. Uno que otro carro se desliza por la calzada húmeda. El barrio duerme, pero mi gato y yo velamos, nos resistimos a dar por concluida la jornada, sin haber hecho nada, al menos yo, que la justifique, que la dote de significación y la diferencie de las otras, igualmente parsimoniosas y vacías. Quizás por eso escribo páginas como ésta, para dejar señales, pequeñas trazas de días que no merecían figurar en la memoria de nadie. En cada una de las letras que escribo

\footnotetext{
${ }^{1}$ De todo ello es muy ilustrativo el relato en forma de cómic que hace Guy Delisle del secuestro que sufrió en 1997 Christophe André, miembro de una ING médica en el Cáucaso. El lenguaje gráfico insiste en una reiteración de encuadres y motivos que trata de traducir visualmente esa monotonía. No extraña que el personaje, en medio de su cautiverio, diga: «Esta noche, nada, como siempre» (Delisle 2016: 267).

${ }^{2}$ En este sentido conviene recordar las palabras de Kafka que escribe el 25 de diciembre de 1915: «He abierto el diario con la intención especial de facilitarme el sueño. Veo precisamente la última anotación y podría imaginar miles de anotaciones de idéntico contenido escritas durante los últimos tres o cuatro años» (2005: 307).
} 
está enhebrado el tiempo, mi tiempo, la trama de mi vida, que otros descifrarán como el dibujo en la alfombra (1986: 118).

La escritura de esos momentos insignificantes parece pugnar contra la monotonía de los días. El diario puede buscar su materia en los momentos en los que no había nada reseñable. Pessoa escribía en noviembre de 1915 en sus diarios del siguiente modo: el día 20 anotaba: «Día vacío, del tipo perdido» (2009: 107). Al día siguiente la lacónica anotación era del mismo tenor: «Lo mismo que el anterior» (2009: 107); el 22 se iniciaba con la frase «Lo mismo», el 23 lo hacía con «La misma clase de cosas». Son numerosas las anotaciones de esta índole. Así los días 3, 4 y 5 de diciembre se despachan apenas con un «Nada juera de lo ordinario estos días, que pasaron tranquilamente» (2009: 111). A veces Pessoa constata tan sólo el hueco y la escritura paradójicamente es el reflejo de la nada, del olvido. El 28 de febrero de 1913 escribía: «Habiendo olvidado escribir la página de este día, perdí perdía el recuerdo de lo que hice, excepto de algunas cosas, pocas, para ciertos fragmentos de varias cosas que tengo en proyecto» (2009: 64) .

Por esta razón - confeccionar una escritura que articule la existencia y la haga narrable — podría entenderse la necesidad ${ }^{4}$ con la que es vista por parte de su autor. No se trata de un artificio sin más, de una retórica aprendida; el diario posee un fuerte componente confesional y catártico. Esto le lleva a Alejandra Pizarnik a preguntarse el 21 de julio de 1955: «¿Cómo podría vivir sin este cuadernillo? ¡Imposible imaginarlo!» (2003: 37) ${ }^{5}$. Esa necesidad confesional, no obstante, lleva implícita una angustia que le lleva a plantearse su esterilidad. Julio Ramón Ribeyro hablaba de la ausencia de interés de la materia del diario para un posible lector. El 14 de junio de 1958 iniciaba así su entrada: «Nuevamente estas páginas... ¿Para qué? Escribir cosas que a nadie interesan» (2003: 185). Se configura así una suerte de escritura silenciosa, lejana en un principio a la idea de publicación por el hecho mismo de estar en continua ebullición. Esto impide precisamente pensar en la idea fosilizadora de un final. Más que de un texto se trata de una escritura cuyo proyecto es ordenar y explicar, pero también callar, los demonios interiores. Todo ello, no obstante, puede, a ojos de quien escribe, no presentar interés para quien lee ${ }^{6}$. Esa ausencia de destinatario definido derivado acaso de un fracaso

\footnotetext{
${ }^{3}$ El 25 de marzo de ese mismo año -1913- escribía: «(Han pasado varios día sin que le preste atención a este diario). De este día no me acuerdo». (2009:76). Sin abundar más, solo refiero otro par de ejemplos más que corresponden al 28 y 29 de marzo, que poseen idéntica anotación: (Excluido por retraso y olvido)». (2009: 77). Ya no solo se trata de un diario como trabajo en marcha sino del olvido a la hora de reconstrucción de ese día a día que parece hacerse a posteriori.

${ }^{4}$ Me acojo a las palabras del prólogo con el que Tomás Sánchez Santiago acompaña a su edición de los diarios de la pintora zamorana Delhy Tejero. Véanse las páginas dedicadas al concepto de 'escritura de la necesidad' (2004: 10-13).

${ }^{5}$ Para un estudio panorámico y desde una perspectiva múltiple sobre el silencio remito a la tesis de doctorado de Rosa María Mateu Sarra, quien le dedica unas páginas a la importancia del silencio en autores como Pizarnik y Juarroz (2001: 52-60) y también a las páginas de Pozuelo Yvancos (2005).

${ }^{6}$ Son de especial interés las causas que esgrimió Zygmunt Bauman para justificar el inicio de la escritura de un diario. La primera entrada, fechada el 3 de septiembre de 2010, se iniciaba de esta manera: «Lo confieso: estoy empezando a escribir (son las cinco de la mañana), no tengo ni la menor idea de qué seguirá, si es que sigue algo, ni de por cuánto tiempo seguirá, ni de hasta cuándo necesitaré y sentiré el impulso de seguir. Y ni la intención ni, menos aún, la finalidad están en absoluto claras» (2012:11). Añade a esto otras consideraciones muy pertinentes sobre el proceso que activa la escritura del diario. Entre sus causas están la necesidad de escribir sea lo que sea, de ordenar, también, sus pensamientos esparcidos y fragmentarios: «al parecer, soy incapaz de pensar sin escribir... Supongo que, antes que escritor, soy lector: hay toda una serie de retazos, fragmentos, partes y pedazos de ideas que pugnan por nacer, cuyos fantasmagóricos (aterradores, incluso) espectros se arremolinan, se amontonan, se condensan y se disipan una y otra vez, y que solo a ser captados y atrapados
} 
comunicativo explica que a veces se haya visto en el diario un tipo de escritura comparable a una conversación con uno mismo: «Creo haber encontrado la razón intrínseca de los diarios íntimos: tenerse a sí mismo por interlocutor» (Ribeyro, 2003: 80). Pensar en el hecho de quién pueda ser el destinatario del diario y las posibles soluciones que se han buscado es una cuestión que no conviene perder de vista. Una de las posibilidades, como ya se ha visto, es que el destinatario sea uno mismo. Así existe un desdoblamiento en escritor y relector de ese texto. Las palabras de Kafka el 19 de noviembre de 1913 son muy ilustrativas: «Me conmueve la lectura del diario. ¿Será debido a que en la actualidad no tengo ya la menor seguridad? [...] Ahora me siento más inseguro que nunca; sólo siento en mí la violencia de la vida. Y estoy inmensamente vacío» (2005: 206). El escritor se comunica consigo mismo desdoblado a modo de lector. En el diario se ve de forma manifiesta el carácter especular que posee la escritura. Si en ocasiones la lectura de su diario conmocionaba a Kafka tampoco es infrecuente que sirva para comprender su propia vida: «He hojeado un poco el diario. Me ha proporcionado una noción de cómo está organizada una vida como la mía» (2005: 275, 15 de octubre de 1914). Esta capacidad reflexiva puede provocar a veces una retroalimentación. Kafka nos ofrece de nuevo un buen ejemplo. El veintisiete de junio de 1919, tras haber enmudecido su diario en 1918, escribe unas escuetas notas que parecen más bien la agonía de una escritura que se sabe destinada al silencio definitivo: «Nuevo diario; en realidad escribo sólo porque he leído el viejo.» (2005: 341). Sin embargo, también es posible buscar un interlocutor más allá de uno mismo. La escritura diarística reclama entonces una capacidad comunicativa muy cercana al funcionamiento epistolar ${ }^{7}$. Ambas pertenecen al mundo de la intimidad, sólo que una busca una transitividad. Se puede entender así la operación de lectura del diario propio a otra persona como un intento de superar ese déficit comunicativo que comportaba la creación del diario. Un buen ejemplo de ello puede ser Kafka y su decisión de leer a su amigo Max Brod partes de su diario:

\footnotetext{
por nuestros ojos, podemos inmovilizar, fijar y acotar dentro de unos contornos. Y deben escribirse uno detrás de otro para que la idea [...] nazca por fin, o para que, en caso contrario, sea abortada o- -si ha llegado ya muerta a este mundoenterrada para siempre» (2021:12). Sigue con su exposición de motivos para iniciar ese diario y entre ellos ocupa un lugar muy destacado la soledad en la que vive tras la muerte de Janina. Su rostro, en el ordenador, invita a un diálogo. Escribir ese diario es un paliativo para esa soledad: «El rostro de Janina es la primera imagen que veo al encender mi ordenador de sobremesa, así que desde el momento en que abro el Microsoft Word no hago más que entablar un diálogo. Y dialogando es impensable que me sienta solo» (2012:12). Junto a los motivos ya enunciados: la necesidad de escritura, la escritura como forma de ordenar el pensamiento y la escritura como fármaco contra la soledad se inscribe otro motivo especialmente interesante: la concepción de una escritura diarística como un espacio marginal desde el que seguir hablando cuando el discurso principal de Bauman comenzaba a diluirse ante la velocidad, complejidad y dispersión de la realidad a la que asiste perplejo. Su diario es una forma de resistencia, de no querer jubilar su curiosidad pero también, y en cierto modo, es la constatación de un silencio, de una renuncia a establecer grandes sistemas explicativos. Se acoge al ejemplo de Wittgenstein y su recomendación de guardar silencio sobre aquellas cosas sobre las que no se puede o no se sabe hablar. El diario es, entonces, un hablar desde la periferia cuando el discurso central se había silenciado.

${ }^{7}$ Ribeyro pone también de manifiesto la relación entre el diario y la carta: «Las relaciones entre los diarios íntimos y la correspondencia son en cambio más estrechas. Exagerando un poco podría decirse que las páginas de un diario son cartas que el autor se dirige a sí mismo y que las cartas son páginas de un diario que se dirigen a una persona» (1953: 10). No lejos de esa concepción está la idea de Jules Renard que aplica a toda su obra: «Mi literatura: cartas a mí mismo que os permito leer.» (2008: 73) Un caso singular lo presenta la pintora Delhy Tejero que utiliza a sus cuadernos como interlocutores. Cada cuaderno posee, además, su propio nombre que lo singulariza y lo dota de personalidad. Como pequeña muestra sirvan estas palabras de 16 de agosto de 1938: «No sé vivir. Pierdo el tiempo. Quiero contarte cualquier cosa, "Simona", casi nunca te llamo por tu nombre, cuadernín» (2004:183).
} 
Me perturba el hecho de que esta mañana haya estado hojeando el diario, para ver lo que podría leerle a M. Pero al efectuar esta revisión, no he descubierto que lo escrito hasta ahora tenga un valor especial, ni que deba tirarlo sin más. Mi sentencia se sitúa entre ambas opiniones, más cerca de la primera, aunque no es tal que, a juzgar por el valor de lo escrito, deba considerarme agotado, a pesar de mis debilidades (2005:137, 31 de diciembre de 1911).

Por su parte, Alejandra Pizarnik también albergó la idea de escribir un diario que tuviese un interlocutor pisando así un terreno intermedio entre el diario y la carta: «Lo mejor que se me ocurre es una especie de diario dirigido a (supongamos, Andrea). Es decir; no serían cartas ni un diario común.» $(2003: 30)^{8}$. Mansfield escribía el 14 de febrero de 1916:

Querido hermano, mientras escribo estas notas estoy hablando contigo. ¿A quién le escribí cuando llevaba esos grandes diarios quejosos? ¿Era a mí misma? Pero ahora, mientras escribo estas palabras y hablo de lograr el clima de Nueva Zelandia, te veo frente a mí, veo tus ojos pensativos que me miran. Sí, es para ti (1978:41).

Parece como si en el impulso primigenio de un diario hubiese un deseo del confidente imposible. La aspiración a ser una carta o una conversación con uno mismo son metáforas de esa ansiedad.

El carácter confesional, no obstante, no impide que la idea de abandono ronde la cabeza del diarista desde sus inicios. En fechas tempranas, 12 de febrero de 1951, Ribeyro anunciaba su propósito de liquidar el diario: «Estoy decidido a liquidar de una vez por todas este diario. No puedo escribir una página más en él. Ha sido una ocupación inútil. Basura, como todo lo que he escrito fuera de él» (2003:9). La tentación de abandono, curiosamente, viene regulada por un prurito de calidad. No deja de ser curioso cómo el diario, que puede tener una finalidad catártica, es juzgado a posteriori, y en el caso de los escritores, como una obra literaria. Ese juicio, que a veces hace hincapié en la falta de calidad, lleva a esta escritura a un terreno peligroso: el de su posible desaparición ${ }^{9}$. El propio Ribeyro anota el 22 de julio de 1969 su operación de relectura y purga de estos diarios. En cierto modo puede verse otra amenaza hacia esa escritura de la necesidad que en su origen define al diario. La relectura impone una falsilla literaturizante sobre la que juzgar aquello que se escribió quizás en muchos casos sin pretensiones literarias. La expresión surgida de la intimidad es analizada críticamente desde otro tiempo. La relación de esta relectura con el silencio es doble: por un lado el análisis propone la supresión e incluso destrucción de parte del diario ${ }^{10} \mathrm{y}$, por otro, la visita a un tiempo pasado fijado en

\footnotetext{
${ }^{8}$ Un buen ejemplo de todo esto lo ofrece Manuel Alberca al extractar un pasaje del diario de una adolescente: «Verás, hoy se me ha ocurrido una idea, y será que para que la lectura de este libro no resulte tan monótona, me siento inclinada a contarle la vida a una amiga, y esa amiga serás tú». A esto comenta Alberca: «La invención del interlocutor ideal resulta clave para paliar la soledad de la que nace y, paradójicamente, se alimenta el diario» (2003: 27).

${ }^{9}$ La misma puede verse en Virginia Woolf. El 7 de octubre de 1919 veía así su propio diario: «He empezado a leer el primer volumen de mi diario; y veo que el segundo aniversario se cumple ahora. No creo que el primer volumen sea tan bueno como el último, una prueba de que toda literatura, incluso estos garabatos improvisados, posee una forma que exige un aprendizaje. ¿Vale la pena continuar?» (1992:149)

10 «Relectura de mis "diarios íntimos” que hoy me llegaron de Lima. Diarios discontinuos que abarcan diez años: de 1950 a 1960 [...] Los primeros de estos diarios, de 1950 a 1955, están ya irremisiblemente condenados y serán arrojados al fuego. Tal vez sólo guarde algunos extractos sobre cosas muy concretas. Perecerán como perecieron los que escribí de 1946 a 1949 y que contenían, según me enteré hoy, notas de lecturas y otras sandeces por el estilo» (2003:353). En otro lugar Ribeyro ya había realizado una relectura crítica del diario que lo llevaba hacia una forma de silencio: «Relectura de mi diario, un poco a vuelo de pájaro deteniéndome aquí y allá. Empecé por el cuaderno más viejo: el del año 1950. Hace algún tiempo destruí los de los años 47,48 y 49 que estaban dedicados en su mayor parte a comentar los libros que leía. El
} 
la escritura conlleva la constatación de lo que había sido olvidado. Muchos de los nombres o experiencias habían sido desalojadas de la memoria ${ }^{11}$. De ahí la importancia del diario.

Esta idea del abandono, sin embargo, suscitará el sentimiento de culpabilidad. Esto se ve claro nuevamente en el diario de Ribeyro. La anotación del 20 de mayo de 1951 anuncia su deseo de volcarse sobre el mundo y abandonar el diario:

Quiero terminar este cuaderno con una página que espero sea definitiva. No quiero continuar este diario. Gregorio Marañón me ha abierto los ojos a una realidad presentida: «Todo diario es un lento suicidio.» Soy muy cobarde para quitarme la vida. Por lo demás, mi «yo» es un motivo decepcionante de observación. El mundo es más atractivo. Debo volcarme en él (2003: 13).

Sin embargo, cinco meses después, cuando regresa al diario, se puede leer lo siguiente:

Cuando uno se ha acostumbrado al diálogo interior, es doloroso interrumpirlo. Después de algunos meses de silencio vuelvo a tomar la pluma para escribir este diario, sintiéndome algo desmoralizado y hasta cierto punto culpable [...] Culpable, por haber abandonado este cuaderno a expensas de mi poca fortuna en la arena de los fuertes (2003: 13).

Si en momentos parece haber un empeño decidido en abandonar la empresa del diario, no deja de ser significativo el compromiso adquirido con la propia escritura que obliga en ocasiones a su reanudación. Cuando existen esos hiatos en la escritura, los huecos visibles que comporta todo diario, parece observarse la necesidad de aclarar los motivos de ese silencio o, al menos, hacer una referencia a ese silencio ${ }^{12}$. Son normales frases como «Casi un mes que no llevo este cuaderno» (2003: 129),

cuaderno del 50 es casi ilegible, salvo cuatro o cinco páginas que no he tarjado. El cuaderno verde de París es interesante pero tiene mucha basura. El cuaderno verde de Munich es flojo. Las páginas de Mortsel están mejor. Sólo entonces comencé a darme cuenta de que el diario formaba parte de mi obra y no solamente de mi vida. Los mejores son los diarios de Berlín y de Lima a mi regreso. En ellos creo haber encontrado un estilo de diario íntimo: un estilo apretado, expresivo que interesa no solamente como testimonio sino también como literatura» (2003: 209-210). Llama la atención esta actitud crítica del escritor con respecto a sus diarios con la imagen que sobre el diario ofrece desde la perspectiva del lector Alain Girard cuando afirma: «Esas confidencias sobre sí mismo, que recoge día a día, responden a las expectativas del público. El diario no se habría convertido en un género literario si no encontrase una multitud de lectores, que sienten una ardiente necesidad de tales revelaciones. Tampoco a ellos parece bastarles la obra. Lo que quieren son detalles sobre el autor, y un conocimiento íntimo de su persona. [...] Diríase, en última instancia, que la obra importa menos que el limo del que ha brotado» (1996: 32). Esa relectura crítica de los propios diarios se observa también en Sandor Marai: «He enviado por correo el manuscrito de Diario 1976-1983 y las notas seleccionadas. Supongo que será el último volumen de diarios publicado antes de mi muerte. Me falta motivación para redactar las notas finales, me siento como el que ha trabajado muchas horas extra; no tiene sentido anotar y registrar las cosas en la Nada» (20 de junio de 1984) (Marai 2008: 45).

${ }_{11}$ Por esta razón puede verse en ocasiones cómo el diarista se lamenta de no haber puesto por escrito sus experiencias que, al haber sido olvidadas, quedarán relegadas para siempre al silencio. Escribe Ribeyro: «Muchas son las experiencias que he tenido antes, en el transcurso y después de mi viaje a Europa. Libros, amigos, ciudades han desfilado delante de mí con se pequeña carga de enseñanzas. Alguna vez estuve tentado de reseñar algunas de esas experiencias, pero el temor de caer nuevamente en el diario íntimo me detuvo. Ahora lo lamento. Momentos preciosos para mí han muerto o yacen confundidos en la maraña de mis recuerdos» (2003: 21). En esa línea se mueve el comentario de Sylvia Plath: «Es imposible "reproducir la vida" sin tomar apuntes. Ahora estoy furiosa porque, con la excepción de la nieve, he olvidado cómo fue el viaje desde Francia a Munich» (1996: 223).

12 Son curiosas las relaciones entre el diario y otras facetas de la vida y la escritura. Para el caso de Ribeyro, por ejemplo, podría verse cómo el diario establece unas relaciones conflictivas con la propia vida: «Interrumpido este diario por cerca de cuatro meses. Interrupción voluntaria nacida en la idea curiosa de que la notación del diario absorbe mi vida activa» (2003: 173). También podría verse, siguiendo con el ejemplo de Ribeyro, una suerte de interferencia entre la escritura del diario y la ficción. Ambas parecen anularse. La imposición de una parece silenciar a la otra. Se trata de un diario esterilizante frente a otro tipo de diarios, caso paradigmático podría ser el de Kafka, en el que se inscriben bocetos que son como primeros ensayos de obras de ficción escritas más tarde. Vendrían a ser éstos unos diarios productivos cuya inercia 
«Amberes... ¡cuánto tiempo ha pasado desde mi última página de cuaderno! ¿Veinte días?, ¿cuarenta días?» (2003: 135), «Interrumpido este diario por cerca de cuatro meses. Interrupción voluntaria nacida en la idea curiosa de que la notación del diario absorbe mi vida activa [...] Suspendido el diálogo conmigo mismo, mi contacto con el mundo se ha desarrollado con más facilidad» (2003: 173) ${ }^{13}$.

En algunos diarios, como el de Virginia Woolf, el silencio y la interrupción del diario llegan a convertirse en motivos recurrentes. Así reza en la entrada del 8 de agosto de 1921:

¡Vaya laguna! Me hubiera quedado estupefacta si me hubieran dicho, cuando escribí aquí la última palabra el 7 de junio, que una semana después estaría en cama y que no me recuperaría del todo hasta el 6 de agosto: dos meses completos en blanco. Estas palabras, esta mañana, son las primeras que escribo — si esto es escribir — desde hace sesenta días [...] Permitidme que haga votos para que no se repita nunca más (1992: 209).

En el diario de Woolf parece instaurarse la obligación de escritura y reseña de toda actividad social, de ahí que el 26 de septiembre se escriba: «Han pasado muchas cosas que no he registrado en el diario. Éste ha sido nuestro verano más sociable» (1992: 238). Esa obligación escritora lleva a decir: «quisiera dejar el menor número de páginas en blanco, y para fin de año sólo faltan tres semanas» (1992: 271).

Cuando se trata de rellenar un hueco del diario se consigna algo que ya no sucede. El diario se convierte en un relato retrospectivo que posee una inercia y ésta le obliga a intentar justificar sus brechas. En casos como el de Virginia Woolf parece haberse contraído un compromiso con la vida pública como parece deducirse de su anotación del 12 de julio de 1919: «En lo que a la vida pública se refiere, veo que he olvidado decir que se firmó la paz» (1992: 141). En la siguiente entrada, tan solo una semana después: el 19 de julio, afirma: «Tendría que decir algo sobre el Día del Armisticio, supongo, aunque no sé si la ocasión merece estrenar una pluma nueva» (1992: 142). No extrañará, pues, que al día siguiente tras haber narrado los desfiles militares escriba en otra entrada: «Quizá termine aquí el relato de la celebración de la paz» (1992: 143). Queda bien claro que la vida exterior parece marcar el ritmo y la temática de una expresión que parecía muy ligada a la intimidad. En cierto modo la escritura de la necesidad parece haberse desplazado hacia otra escritura que tiene que ver más con la obligación. Será este carácter implícito de obligatoriedad lo que realce esas lagunas de silencio que jalonan todo diario. Así se expresa el 11 de junio de 1922: «iQué vergüenza! ¡Qué vergüenza! Desde el 27 de abril hasta hoy, no he anotado una sola palabra» (1992: 28). En ocasiones la imposibilidad de reflejar todo lo sucedido en el lapso de uno de esos intervalos de silencio puede con la «obligatoriedad» de esa escritura diarística. Así escribe el 2 de noviembre de 1921: «Debería

parece relacionada con un impulso centrípeto. El diario es entonces un taller de escritura (Trabado 2007; Rabí do Carmo 2014). Sobre esa idea esterilizante del diario son muy elocuentes las palabras de Jules Renard. En la entrada del 15 de junio de 1897 afirma: «Me duelen las ideas. Mis ideas están enfermas, y no me avergüenzo de esta enfermedad secreta. Ya no le encuentro gusto no solo al trabajo, sino tampoco a la pereza. Ningún remordimiento por no hacer nada. Estoy cansado como si hubiera dado la vuelta al universo. Creo que he tocado el fondo de mi pozo.

¡Y este Diario que me distrae, me divierte y me esteriliza! Trabajo una hora, en enseguida me siento deprimido, y hasta escribir lo que escribo me hastía» (Renard, 2008: 124).

13 «Larga interrupción del diario. Pérdida del sentido de lo pintoresco. Búsqueda de lo esencial. Inquietud. Esperanza de realizar algo importante. Buscar la tensión, en la que brotan las chispas del lenguaje» (2003: 227). 
ocuparme de las cinco semanas, o casi, omitidas; pero no puedo, de verdad; pues he visto a demasiada gente, y han sucedido muchas cosas; así quedémonos donde estamos» (1992: 214). El diario se convierte en una especie de crónica en la que se enfatiza la mirada personal pero parece haberse descartado la posibilidad de una escritura que entre de lleno dentro de un mundo que parecía haberle pertenecido desde el primer momento: la intimidad. La propia escritora es consciente de la restricción autoimpuesta a su escritura:

Me interesa mucho que este diario llegara a convertirse en un diario de verdad. Pero para eso haría falta que yo hablara del alma y ¿no me prohibí hablar del alma cuando lo empecé? Lo que sucede es que, como siempre, cuando me pongo a escribir sobre el alma la vida se interpone. (1992: 254, 19 de febrero de 1923).

Contrasta en cierta manera esta actitud con la mostrada por Ribeyro. Los acontecimientos históricos no marcan la pauta ni imponen esa dirección de obligatoriedad. Si Virginia Woolf sentía la necesidad de que su diario hablase del armisticio, Ribeyro realiza una lacónica referencia al mayo del 68 parisino. La causa es la complejidad del asunto que se quiere referir; sin embargo, apenas se realiza un análisis o se expresa una opinión. Se utiliza el diario como una especie de tablón en el que se señala el momento crítico, nada más. En ese caso podría hablarse de una especie de función de anclaje temporal que funcionaría de manera análoga a las fechas de cada entrada. Sin embargo, se trata de un tiempo público y el diario ofrece una escritura secreta. Quizás esto explique esa tendencia autista de un discurso íntimo como es el caso de Ribeyro que se distancia en su praxis de manera radical a lo visto en Virginia -Woolf. De alguna manera se perfilan dos formas de administrar el silencio sobre ciertos acontecimientos ${ }^{14}$. El miedo a cargar las tintas sobre el ámbito de la intimidad llevaba a Woolf a un tipo de escritura relacionada con la crónica que explica el temor a que esas lagunas propias del texto acaben por diluirlo hasta silenciarlo. Por su parte, Ribeyro encarna otro tipo de diario en el que lo privado tiene una gran importancia (Gnutzmann: 2004). Sus silencios vienen dictados por otras causas que son de índole interna. Se trata de una progresiva conciencia crítica que lleva a la destrucción de éstos, crítica que acaba también por someter a toda su obra a un proceso de frustración y fracaso que le impone silencios y da cuenta del truncamiento de sus proyectos ${ }^{15}$. Si en la escritura primigenia del diario puede existir un afán de confesión que emana de los ámbitos privados y que se marca la necesidad de llevar esa escritura como una actividad clandestina, es decir, silenciosa, no deja de ser interesante cómo esa clandestinidad puede evolucionar hacia un vuelco a lo externo: son entonces los acontecimientos los que imponen un serie de hitos y exigen cierta obligatoriedad en el cultivo de esa escritura provocando así una disculpa por las lagunas textuales o bien puede derivar en una suerte de autoconciencia crítica que acabe por anular al individuo y su escritura. El fracaso del diálogo con uno

\footnotetext{
${ }^{14}$ Béatrice Didier (1996) refleja de forma muy certera estos dos tipos de diarios. Habla de diarios reportaje frente a diarios introspectivos. Partiendo de esa base, podría verse cómo cada uno de ellos, partiendo de una filosofía común, muestra una forma diferente de encarar esos silencios que son consustanciales a la escritura del diario.

${ }^{15}$ Podría relacionarse este tipo de silencio con lo que José Antonio Marina define como «El fracaso de la voluntad» (2004). También son de interés las páginas que dedica a lo que denomina «Los lenguajes fracasados» (2004: 77-96).
} 
mismo puede también abocar la escritura hacia su silencio definitivo ${ }^{16}$. Lo que nacía como una necesidad también va creando lagunas, las entradas del diario se espacian hasta que finalmente disuelve su voz en la nada ${ }^{17}$. Lo que era una tabla de salvación ya no sirve y esa confesión se acoge ahora al silencio, no como síntoma de sabiduría sino como derrota vital. El dolor no siempre es cifrable en palabras. Puede el dolor ser tenaz en su persistencia pero a la escritura le está vedado repetirse a modo de eco. Esas entradas, como las de Kafka, proclamando tan sólo «no he escrito nada» parecen estertores de una voz en agonía constante con el querer decir. El dolor y la quiebra vital puede ser algo muy largo de vivir pero su narración a veces cabe en unas líneas. El «nada» de Kafka traducía apenas en una palabra un proceso doloroso muy complejo que no encontraba en su escritura suficientes matices para ser descrito. Tras el examen crítico al que el diarista somete su escritura es posible que no quede otra solución que el silencio. Si en el origen de esta escritura privada estaba el silencio, si también el silencio se encuentra inscrito en la estructura fragmentada del diario con el que se establece un compromiso tácito que obliga a aclarar los motivos de ciertas lagunas, también el silencio está en la etapa final como constatación del fracaso de la palabra, incapaz de retorcerse para decir de otra manera, parece una exigencia sólo aplicable al lenguaje y no al padecimiento, lo que era una rutina en el sentir vital. A diferencia de la narración que conduce a un punto de llegada dictado por una resolución de la lógica interna, la finalización del diario es arbitraria. ¿Cuándo finalizar un diario? La respuesta no puede sino ser inquietante ${ }^{18}$. Valgan, de nuevo, las palabras de Sandor Marai: «no tiene sentido anotar y registrar las cosas en la Nada».

\section{Bibliografía}

AlbercA, M. (2003): «La escritura invisible de las muchachas», Memoria. Revista de Estudios Biográficos, 1, pp. 18-32.

BAUMAN, Z. (2012): Esto no es un diario. Barcelona, Paidós.

CABAllÉ, A. (1995): Narcisos de tinta. Ensayos sobre la literatura autobiográfica en la lengua castellana (siglos XIX y XX). Málaga, Megazul.

CASTIlla DEl PINO, C. (Comp.) (1992): El silencio. Madrid, Alianza.

\footnotetext{
${ }^{16}$ Podría verse ese silencio como una forma definitiva de replegarse sobre el espacio de lo íntimo. Tengo en cuenta la distinción entre lo íntimo, privado y público que realiza Carlos Castilla del Pino (1996). Si en la búsqueda de un receptor (ansiedad del diario por convertirse en una carta) se basculaba de lo íntimo hacia lo privado a través de la confidencia, la asunción de ese fracaso supone la renuncia a ese movimiento que revertía, a través de la escritura y un destinatario a veces inventado, en un autoanálisis que podría ser, paradójicamente, esterilizante para con la expresión verbal. Vuelvo sobre las palabras de Ribeyro en las que realiza un certero análisis de los motivos del diario. La cita corresponde a parte de la entrada fechada el 29 de enero de 1954 y en ella se hace explícita todos esos silencios que habitan la superficie del diario. Tras referir como uno de los catalizadores del diario el sentimiento de culpabilidad y la escritura como una confesión al margen del rito católico dice: «Habría que aprender a leer entre líneas, descubrir qué hecho concreto ha dictado tal apunte o tal reflexión. Por lo general reanaliza el sentimiento, pero se silencia la causa» (2003: 30). No todo lo del ámbito íntimo pasa a lo privado de la escritura. Hay siempre implícita una fuerte carga de silencio que se hace visible.

${ }^{17}$ Significativa es la entrada de la pintora toresana Delhy Tejero fechada el 22 de Julio de 1938: «Nunca seremos felices porque, pienso yo, cuadernín que se cansa uno antes que se sacia. El arte cuando no hay nada que decir, ¿para qué hacerlo? Si no hay nada, ¿a quién contarlo?» (2004: 178).

${ }^{18}$ Remito a las páginas dedicadas al asunto por Philippe Lejeune (2009).
} 
(1996), «Teoría de la intimidad», Revista de Occidente, 182-183, pp. 15-30.

DelisLe, G. (2016): Escapar. Historia de un rehén. Bilbao, Astiberri.

DIDIER, B. (1996): «El diario ¿forma abierta?», Revista de Occidente, 182-183, pp. 39-46.

GIRARD, A. (1996): «El diario como género literario», Revista de Occidente, 182-183, pp. 31-38.

Gnutzmann, R. (2004): «Acerca de los diarios de Julio Ramón Ribeyro», Cuadernos Hispanoamericanos, 651-652, pp. 171-181.

LeJeune, Ph. (2009): «How do Diaries End?», On Diary. Ed. Jeremy D. Popokin \& Julie Rak. University of Hawai Press, pp. 187-200.

Mansfield, K. (1978): Diario. Buenos Aires, Centro Editor de América Latina.

MATEU SERRA, R. Mª : (2001), El lugar del silencio en el proceso de comunicación. Tesis de doctorado, Universitat de Lleida.

MARINA, J. A. (2004): La inteligencia fracasada. Teoría y práctica de la estupidez. Barcelona, Anagrama.

KAFKA, F. (2005): Diarios (1910-1923). Trad. Feliu Formosa. Barcelona, Tusquets.

PiZARniK, A. (2003): Diarios. Ed. Ana Becciu. Barcelona, Lumen.

Plath, S. (1996): Diarios. Madrid, Alianza.

PessoA, F. (2009): Diarios. Trad. José Álvarez Galán. Madrid, Gadir.

Pozuelo Yvancos, J. M (2005): «Silencios, olvidos. El tejido del otro texto», en De la autobiografía. Teoría y estilos. Barcelona, Crítica, pp. 71-90.

RABído CARMO, A. (2014): «El autor como diarista: La tentación del fracaso, de Julio Ramón Ribeyro», Lienzo, 35, pp. 225-250.

RENARD, J. (2008): Diario 1887-1910. Ed. Josep Massot e Ignacio Vidal-Foch. Barcelona, Debolsillo. RiBEYRo, J. R. (1953): «En torno a los diarios íntimos», en La caza sutil. Lima, Milla Batres, 1975, pp. 9-13.

- (1986): Prosas apátridas. Barcelona, Tusquets.

- (2003): La tentación del fracaso. Prólogos de Ramón Chao y Santiago Gamboa. Barcelona, Seix-Barral.

SÁncheZ Santiago, T. (2004): «Introducción”, en Delhy Tejero, Los cuadernines (Diarios 19361968). Eds. Mª Dolores Vila Tejero y Tomás Sánchez Santiago. Zamora, Diputación de Zamora, pp. 9-32.

TEJERo, D. (2004): Los cuadernines (Diarios 1936-1968). Eds. Ma Dolores Vila Tejero y Tomás Sánchez Santiago. Zamora, Diputación de Zamora.

TRABADO CABADO, J. M. (2007): «La escritura del fracaso o la realización paradójica: para una poética narrativa de Julio Ramón Ribeyro», Non Omnis Moriar. Estudios en memoria de Jesús Sepúlveda. Málaga, Anejo de Analecta Malacitana (Anejo LXV), pp. 405-433.

Woolf, V. (1992): Diario íntimo I (1915-1923). Traducción de Justo Navarro. Madrid, Mondadori. 